\title{
Near-infrared fluorescence imaging with indocyanine green for assessment of donor livers in a rat model of ischemia-reperfusion
}

Liyu Shan ${ }^{1}$, Huan Chen ${ }^{1,2}$, Lifei Yang ${ }^{1}$, Zhe Feng ${ }^{1}$, Yue Wang ${ }^{1}$, Rongfeng Wang ${ }^{1}$, Nana Zhang ${ }^{1}$, Rongqian Wu ${ }^{1}$, Yi LV $v^{1 *}$ and Tao Ma ${ }^{1,3^{*}}$

\begin{abstract}
Background: Although marginal donor livers expand the donor pool, an ideal method for quantitatively evaluating the quality of donor livers has not been developed. This study aimed to explore the feasibility of indocyanine green (ICG) fluorescence imaging for estimating liver function in an ischemia-reperfusion model.

Methods: Forty-eight rats were randomly and evenly divided into 8 groups: the control group and the experimental groups (I-VII). The portal vein blocking period was $0 \mathrm{~min}, 10 \mathrm{~min}, 20 \mathrm{~min}, 30 \mathrm{~min}, 40 \mathrm{~min}, 50 \mathrm{~min}$ and $60 \mathrm{~min}$. After blood flow was reestablished and the hemodynamics stabilized, ICG was injected through the dorsal penile vein as a bolus, and the fluorescence signal was recorded for $30 \mathrm{~min}$ in real time. The fluorescence intensity (FI) curve of the liver was fitted with an asymptotic regression model. Fresh liver tissues and serum were obtained from the middle lobe of the liver on postoperative day (POD) 1 and POD 7 for histopathological evaluation and liver function tests.

Results: The growth rate of the FI curve, parameter b3, decreased from groups I to VII. According to the two sudden changes in b3 (20 min, 50 min), the experimental groups could be classified into 3 groups (A, B and C). Hepatocytes in groups I-II showed slight edema, group III began to show obvious hepatocyte edema and vacuolar degeneration, and in groups VI-VII, severe hepatocyte degeneration, necrosis and large inflammatory cell infiltration were observed. Suzuki's scores in the 3 groups were also significantly different $(P<0.01)$. At the same time, the serum liver function in the experimental groups showed a significant increase on POD 1 and a decrease on POD 7. The alanine aminotransferase (ALT), aspartate aminotransferase (AST), and total bilirubin (TB) levels of groups A, B, and C were significantly different on POD $1(P<0.05)$, and the ALT and direct bilirubin (DB) levels were significantly different on POD $7(P<0.05)$; the lactic dehydrogenase (LDH) level of the group $C$ was significantly higher than that of the groups $A$ and $B$ on $P O D$ 1 and POD 7. Meanwhile, the 7-day survival rate of the rats in group $C$ was poor compared to that of the rats in groups A and B (58.3\% vs. $100 \%$ vs. $100 \%)$.
\end{abstract}

Conclusion: ICG fluorescence imaging is effective for estimating the degree of liver damage and grading in an ischemia-reperfusion model. It probably has the potential for use in assessing the quality of the donor liver in liver transplantation.

\footnotetext{
*Correspondence: luyi169@126.com; mataodr@163.com

${ }^{1}$ National Local Joint Engineering Research Center for Precision Surgery

and Regenerative Medicine, First Affiliated Hospital of Xi'an Jiaotong

University, Xi'an 710061, China

Full list of author information is available at the end of the article
}

(C) The Author(s) 2022. Open Access This article is licensed under a Creative Commons Attribution 4.0 International License, which permits use, sharing, adaptation, distribution and reproduction in any medium or format, as long as you give appropriate credit to the original author(s) and the source, provide a link to the Creative Commons licence, and indicate if changes were made. The images or other third party material in this article are included in the article's Creative Commons licence, unless indicated otherwise in a credit line to the material. If material is not included in the article's Creative Commons licence and your intended use is not permitted by statutory regulation or exceeds the permitted use, you will need to obtain permission directly from the copyright holder. To view a copy of this licence, visit http://creativecommons.org/licenses/by/4.0/. The Creative Commons Public Domain Dedication waiver (http://creativeco mmons.org/publicdomain/zero/1.0/) applies to the data made available in this article, unless otherwise stated in a credit line to the data. 
Keywords: Indocyanine green, Near-infrared fluorescence imaging, Liver function assessment, Donor liver, Ischemiareperfusion injury, Liver transplantation

\section{Background}

The large demand for liver transplantation and the shortage of grafts are bottlenecks and challenges faced in the development of liver transplantation worldwide [1]. With the expansion of liver donor pools, traditional liver donor quality indicators cannot estimate donation after cardiac death $(\mathrm{DCD})$ or marginal livers comprehensively and accurately $[2,3]$. Because the subjective judgment of transplant doctors is limited by experience, pathology and imaging methods are invasive and lack convenience, a unified evaluation standard for liver donors has not yet been formed. It is of great clinical significance to find a noninvasive quantitative evaluation method.

Indocyanine green (ICG) is the only fluorescent imaging substance approved by the Food and Drug Administration (FDA) for use in humans [4]. After entering the human body, it can quickly bind to proteins and is selectively taken up by hepatocytes and excreted through the biliary tract as a prototype without hepato-intestinal circulation. ICG does not participate in biochemical reactions in the body and can be excited by near-infrared light at a wavelength of 760-810 nm, emitting fluorescence at $830 \mathrm{~nm}$. Fluorescence imaging with ICG is widely used as an intraoperative navigation tool for various cancers [59], sentinel lymph nodes [10-14], and blood perfusion of tissues and organs [15-22]. As ICG is metabolized only by the liver, fluorescence imaging with ICG is expected to be ideal for assessing donor livers.

Hepatic ischemia-reperfusion injury (HIRI) refers to the reestablishment of blood flow after the liver endures ischemia for a certain period [23, 24], the inflammatory response increases, and even serious dysfunction occurs. HIRI is one of the main factors influencing the quality of donor livers, and it is closely related to the occurrence of nonanastomosed bile duct stenosis after liver transplantation [25-27]. In this study, we used ischemia time as a variable to investigate the feasibility and effectiveness of the ICG fluorescence imaging system for evaluating liver function in a rat liver ischemia-reperfusion model. We hope to lay the foundation for follow-up research on the assessment of donor livers in rat liver transplantation.

\section{Methods}

\section{Experimental animals and groups}

Forty-eight healthy male Sprague-Dawley (SD) rats weighing 280-320 g were provided by the Experimental Animal Center of Xi'an Jiaotong University. The rats were fed in the animal center, the temperature was maintained at $25 \pm 2{ }^{\circ} \mathrm{C}$, the humidity was controlled at $65-80 \%, 12 \mathrm{~h}$ of light/day were maintained, and the rats had free access to food and water. The animal protocol was designed to minimize pain to the rats in our experiment.

Animal feeding and management strictly followed the national Regulations on the Management of Experimental Animals and the Implementation Rules for the Management Conditions of Experimental Animals in Shaanxi Province. The experimental procedure was approved by the Animal Ethics Committee of Xi'an Jiaotong University and complied with the Declaration of Helsinki.

Before the experiment, all the rats were fasted for $8 \mathrm{~h}$ and allowed to drink freely.

Forty-eight rats were randomly divided into 8 groups evenly. Ligation of the hepatic artery during the operation was performed in the experimental group rats but not in the control group rats. According to the blocking time of the portal vein, the rats in the experimental groups were divided into groups I-VII, with blocking times from 0 to $60 \mathrm{~min}$. The experiment design is shown in Fig. 1.

\section{Equipment and reagents}

The Open Fluorescent Surgical Navigation System (Magnetic Health care, Xi'an, China) and indocyanine green (25 mg, Dandong Yichuang Pharm., Dandong, China) were used. ICG was diluted in sterile water to yield a stock solution of $0.3 \mathrm{mg} / \mathrm{ml}$ for immediate use.

\section{Surgical procedure}

In this experiment, the rats were anesthetized with $5 \%$ isoflurane inhalation. First, each rat was placed into the anesthesia induction box, and the flow valve was opened to the maximum for approximately $2 \mathrm{~min}$. The rat was placed in the supine position after the respiratory rate decreased, the limbs were fixed, a mask was placed on the rat's head, and the flow valve was adjusted to $0.6-0.8 \mathrm{~L} / \mathrm{min}$. All the abdominal skin was shaved and disinfected with povidone-iodine solution. An incision was made on the midline of the abdomen. After ensuring that there were no abnormalities of the abdomen and liver, the falciform ligament and connective tissues around the liver were dissected. The proper hepatic artery was freed from the upper edge of the upper duodenum and ligated with a 6-0 silk suture. Two milliliters of heparin saline $\left(25 \mathrm{U} / \mathrm{ml}, 4{ }^{\circ} \mathrm{C}\right)$ was injected via the inferior vena cava to heparinize the whole body of the rat. The portal vein was moderately isolated and blocked with a clip close to the liver side. 


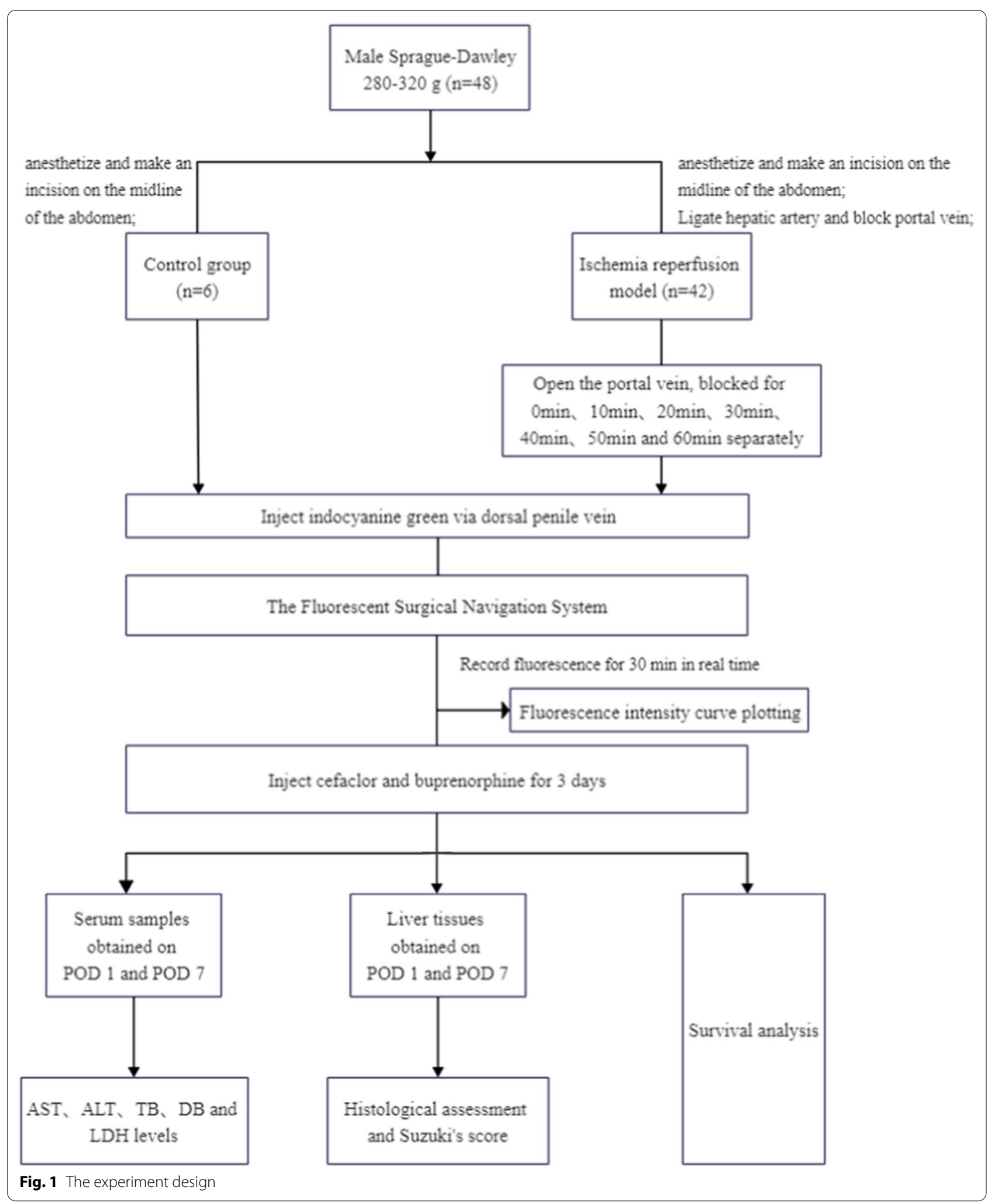


When the portal vein was blocked, a piece of gauze soaked with normal saline at $4{ }^{\circ} \mathrm{C}$ was gently placed to cover the surface of the rat's abdominal cavity to prevent water loss. The method for establishing the experimental groups is shown in Fig. 2a.

After the occlusion times up, the clip was removed to open the portal vein. The ICG solution was then injected via the dorsal penile vein at $0.5 \mathrm{mg} / \mathrm{kg}$. The injection time was set as the 0 point, and real-time recording of the rat liver fluorescence was carried out for $30 \mathrm{~min}$. The process is presented in Fig. 3 with group III as an example. During the imaging process, the posture of the rat was kept constant, and normal saline was dropped on the surface of the organs to keep the abdominal organs moist. At the end of the recording, a dry cotton ball was used to absorb the excess water in the abdominal cavity. Nonabsorbable 3-0 silk sutures were used for two layers of consecutive stitches.

The rats were injected with cefaclor $(16 \mathrm{mg} / \mathrm{kg})$ and buprenorphine $(0.05 \mathrm{mg} / \mathrm{kg})$ for 3 days, subcutaneously on postoperative day (POD) 1 , and intraperitoneally on POD 2 and POD 3.

\section{Sample collection}

On POD 1 and POD 7, the rats in each group were sacrificed by obtaining blood samples through the abdominal aorta. The rat liver was washed with physiological saline at $4{ }^{\circ} \mathrm{C}$ and placed on dry gauze to absorb moisture. Liver tissues of approximately $1 \mathrm{~cm}$ in diameter were taken from the middle liver lobe and placed in a $4 \%$ paraformaldehyde solution for fixation. The serum was separated and stored at $-80^{\circ} \mathrm{C}$ until analysis.

\section{Fluorescence intensity curve}

Image J software was used to process and analyze the fluorescence imaging images of each group. The region of interest (ROI) was selected at the brightest position on the middle lobe of the rat liver, and the average pixel intensity in the ROI was obtained at different times. To accurately analyze the FI and changes, the initial fluorescence intensity was removed from the background fluorescence intensity. Finally, the FI curve was drawn, as shown in Fig. 2b. According to the trend of the curve, the appropriate model to fit was selected, and the various parameters were statistically analyzed.

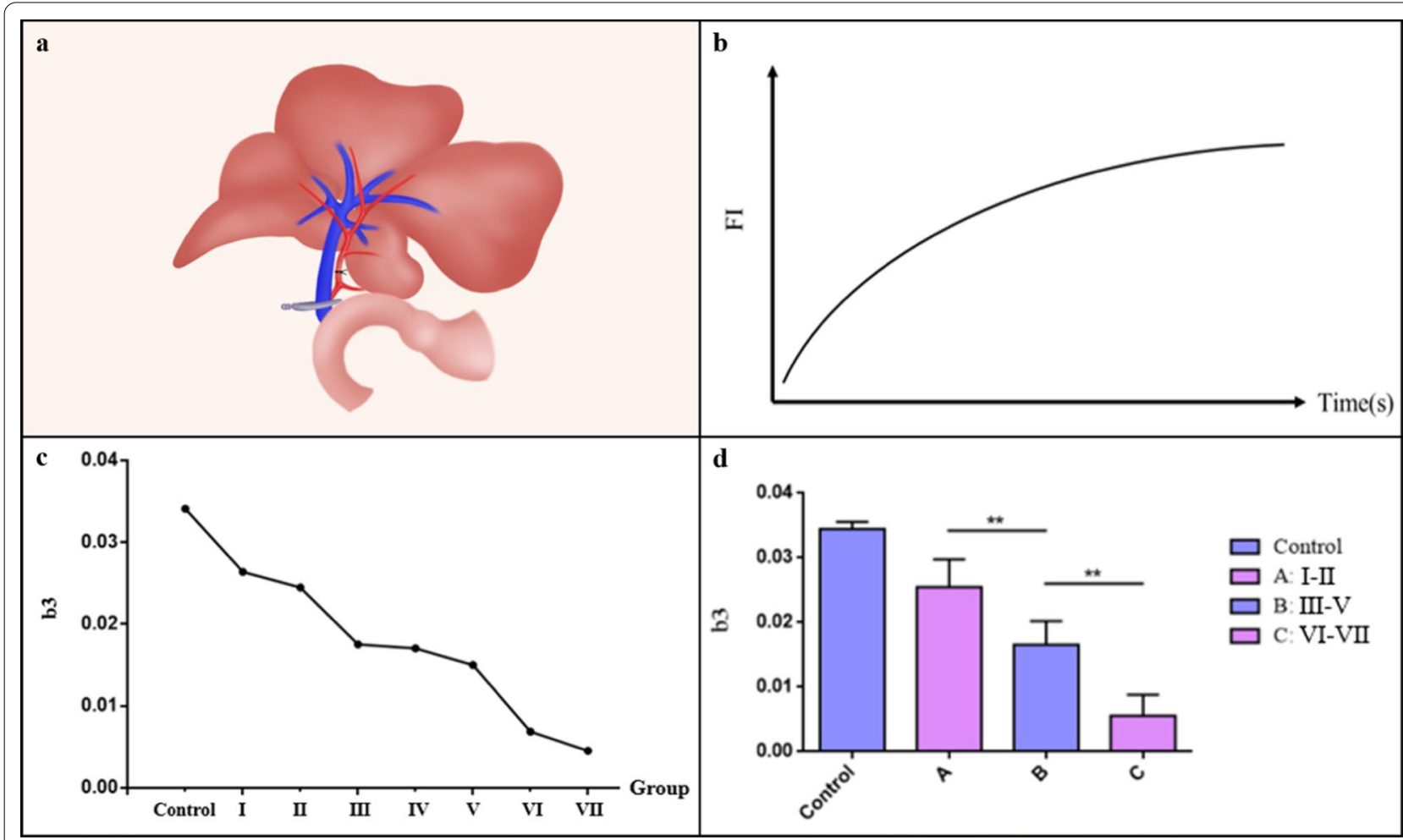

Fig. 2 Surgical method and fluorescence curve analysis. a Method of establishing an ischemia-reperfusion model in rat liver. The hepatic artery was ligated with 6-0 silk sutures, and the portal vein was clamped with microvessel clips; b Fluorescence intensity curve. Fluorescence intensity first grew fast, then slowed, and finally reached a plateau phase; $\mathbf{c}$ We chose the asymptotic regression model to fit the fluorescence intensity curve. Parameter b3, which represents the growth rate of the FI curve, decreased from groups I-VII; d Group A included groups I and II, group B included groups III-V, and group C included groups VI-VIII. Parameter b3 was significantly different among groups A, B and C $(P<0.01)$ 

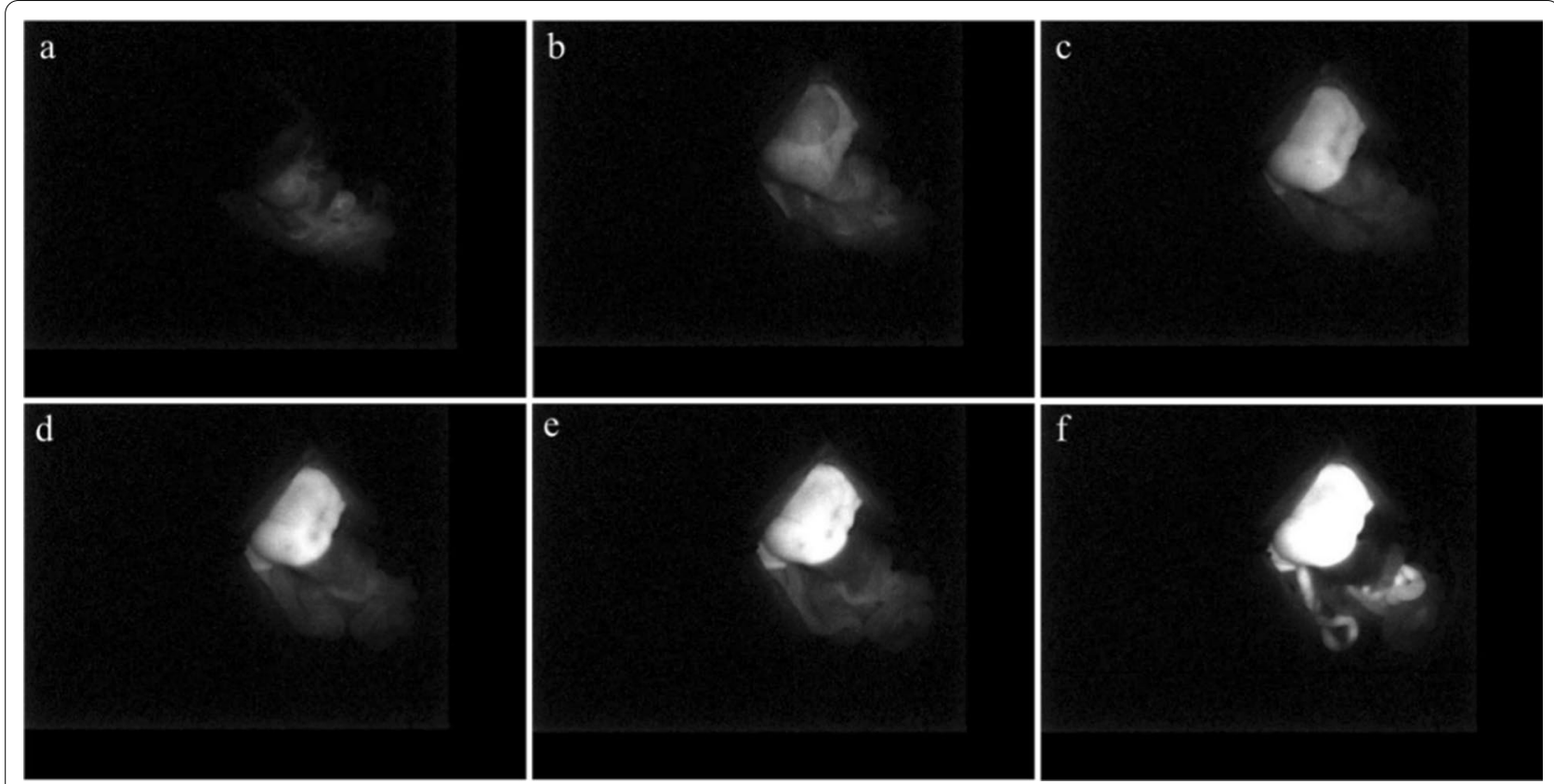

Fig. 3 ICG fluorescence imaging process. a $5 \mathrm{~s}$ after ICG injection; b $15 \mathrm{~s}$ after ICG injection; c 5 min after ICG injection; $\mathbf{d} 10$ min after ICG injection; e 20 min after ICG injection; $\mathbf{f} 30$ min after ICG injection

\section{Assessment of liver function}

Liver function was assessed by measuring the levels of alanine aminotransferase (ALT), aspartate aminotransferase (AST), direct bilirubin (DB), total bilirubin (TB) and lactic dehydrogenase (LDH). Serum samples were obtained on POD 1 and POD 7, and liver function was tested with an automatic biochemical analyzer (Chemray 800, Shenzhen, China).

\section{Histological evaluation of the liver}

The specimens of each group were obtained on POD 1 and POD 7 and fixed with 4\% paraformaldehyde. Paraffin embedding, hematoxylin and eosin staining, dehydration, transparency and mounting were carried out, and then microscopic examination was performed under an optical microscope. The samples were scored according to Suzuki's standard $[28,29]$ to reflect the degree of liver damage as shown in Table 1.

\section{Statistical methods}

IBM SPSS Statistics 24.0 statistical software was used for analysis. Measurement data are expressed as the mean \pm standard deviation $(\bar{x} \pm \mathrm{SD})$, ANOVA and Student's $t$ test were used for comparisons between groups and within groups. $P<0.05$ indicates that the difference is statistically significant.
Table 1 Suzuki's histopathological scoring criteria

\begin{tabular}{llll}
\hline Score & Congestion (\%) & $\begin{array}{l}\text { Vacuolar } \\
\text { degeneration (\%) }\end{array}$ & Necrosis (\%) \\
\hline 0 & None & None & None \\
1 & Very slight (10) & Very slight (10) & Single-cell necrosis \\
2 & Slight $(11-30)$ & Slight $(11-30)$ & Slight $(<30)$ \\
3 & Moderate (31-60) & Moderate (31-60) & Moderate $(31-60)$ \\
4 & Severe $(>60)$ & Severe $(>60)$ & Severe $(>60)$
\end{tabular}

\section{Results}

\section{Fl curve}

The growth rate of the FI curve is fast at first, then slows down, and finally becomes stable. The fitting formula is as follows:

$$
F I(t)=b 1-b 2 \cdot e^{-b 3 \cdot t}
$$

b1 is the upper limit of the FI curve, which represents the maximum fluorescence intensity; b2, an adjustment parameter, eliminates the influence of $b 1$ on the " 0 point", that is, b1-b2 is the initial FI; b3 represents the curve growth rate. $\mathrm{b} 1$ and $\mathrm{b} 2$ between groups were not significantly different $(P>0.05)$; b3 decreased between groups with longer portal vein blocking time, as shown in Fig. 2c. The b3 of groups II and V decreased sharply, and the corresponding portal vein block times were $20 \mathrm{~min}$ 
and $50 \mathrm{~min}$, respectively. We then divided the groups into $\mathrm{A}, \mathrm{B}$, and $\mathrm{C}$ at $20 \mathrm{~min}$ and $50 \mathrm{~min}$, as shown in Fig. $2 \mathrm{~d}$. The decrease in the $\mathrm{b} 3$ value between groups $\mathrm{A}, \mathrm{B}$, and $\mathrm{C}$ was significantly different $(P<0.01)$.

\section{Liver function evaluation}

Compared with those of the control group, the ALT and AST levels of groups I-VII on POD 1 were significantly increased. The increase in groups I-II was smaller than that in groups III-V and VI-VII, and the increase in groups VI and VII was the largest, with a significant difference $(P<0.05)$; the levels of DB and LDH on POD 7 in groups VI and VII were significantly higher than those in groups I-V; the levels of DB and TB in group III were significantly higher on POD 1 than those in groups I-II.

With prolonged blocking time, the ALT and AST levels increased on POD 1 and obviously decreased on POD 7. The ALT and AST levels in groups VI and VII were still relatively high on POD 7, those in the other groups were maintained at a lower level.

The liver function indices, such as ALT and AST, of each group tended to be higher on POD 1 and lower on POD 7. There was no significant difference between the AST, TB, and LDH levels of groups I-V and the control group on POD 7, as shown in Table 2.

\section{Histological evaluation of liver}

As shown in Fig. 4a and d, the hepatocytes (white arrow) in groups I and II had mild edema, the hepatocyte cords were arranged and separated normally by normal hepatic sinusoids (white chevron), and the nuclei were round, large, and centered, without inflammatory cell infiltration. In Fig. 4b, hepatocyte edema (white arrow) occurred in group III on POD 1, and vacuolar degeneration and apoptotic bodies (black arrow) were observed. The degree of hepatocyte edema (white arrow) in Fig. 4e was higher in groups IV and V. The hepatic sinusoids appeared narrow, and the range of vacuolar degeneration and apoptotic bodies (black arrow) was larger on POD 7. As shown in Fig. 4c, the hepatocytes (white arrow) had severe edema, and large areas of hepatocyte degeneration and necrosis were seen on POD 1 in group VII. Besides, necrosis was obvious (white arrow), and large areas of inflammatory cell infiltration (black chevron) were seen on POD 7 in Fig. 4f.

Suzuki's pathological scores were significantly different among the three groups: group $C$ was higher than group $\mathrm{A}$ and $\mathrm{B}$, and group $\mathrm{A}$ had the lowest score $(P<0.01)$ as shown in Fig. 5.

\section{Survival}

The survival curve of each group was analyzed. The rats in the control and I-V experimental groups survived well, and there was no death at 7 days. Seven rats in groups VI and VII died within 7 days after the operation, and 4 of them died on POD 1. The survival curve is shown in Fig. 6.

\section{Discussion}

Since ICG received FDA certification in 1959, it has been widely used as a dye for clinical positioning and visualization, such as in the biliary tract [30-34], in the ureter [35-37], and in hepatocellular carcinoma (HCC) $[8,9,38-40]$. With the deeper development of ICG fluorescence imaging technology, it gradually showed the potential for use in the quantitative assessment of graft function.

In 2010, C. Hoffmann [41] used ICG fluorescence imaging during kidney transplantation and found perfusion defects that are invisible to the naked eye; in 2015, Yoshikuni Kawaguchi [42] found portal vein thrombosis not detected by Doppler ultrasound during liver transplantation, revealing the potential of ICG fluorescence imaging technology for improving the survival rate of transplantation. Fluorescence imaging quantitative assessment of overall liver function was first reported in Narasaki's research [43] and later improved by Damien Dousse [22].

Damien Dousse [22] proposed an exponential model but only observed and measured it for $3 \mathrm{~min}$. The data used for analysis was the first $150 \mathrm{~s}$. No data were excluded in our experiment. After we analyzed our data, we obtained a model consistent with Damien Dousse, but we used the data from the first $30 \mathrm{~min}$ for analysis. Their research suggested that the growth rate of the FI curve is faster in patients undergoing primary nonfunction (PNF) after transplantation and retransplantation. Our conclusions in the ischemia-reperfusion injury model are opposed to theirs. The reason may be as follows: In their study, the experiment was carried out in human liver transplantation, while we developed a rat model of ischemia-reperfusion injury. They had 4 patients with PNF after transplantation and 6 patients with retransplantation. The sample was small, and the quality of the graft was uncontrollable due to the complexity during the surgical operation. However, our research was carried out in animal experiments, the liver ischemia time was controllable, and the sample size was larger.

The FI curve was characterized by 3 phases: an ascending phase, a gentle phase, and a plateau phase, which generally corresponded to the process of ICG metabolism. Perfusion through sinusoids is then taken up, transported, and excreted by hepatocytes to reach equilibrium. We hypothesize that with prolonged ischemic time of the liver, reperfusion injury is more severe, and the ability of hepatocytes to take up ICG is impaired, so the b3 value 
Table 2 Effect of different ischemia times on liver function (mean \pm SD)

\begin{tabular}{|c|c|c|c|c|c|}
\hline Liver function & Control & Group & & POD 1 & POD 7 \\
\hline \multirow[t]{7}{*}{$\operatorname{ALT}(\mathrm{U} / \mathrm{L})$} & $83.26 \pm 10.31$ & A & 1 & $116.28 \pm 14.43$ & $84.34 \pm 5.58$ \\
\hline & & & $\|$ & $158.57 \pm 26.48$ & $73.22 \pm 8.55$ \\
\hline & & B & III & $267.64 \pm 39.82^{\mathrm{a}}$ & $56.27 \pm 5.32^{\mathrm{a}}$ \\
\hline & & & IV & $345.47 \pm 28.92^{b}$ & $74.08 \pm 18.04^{\mathrm{a}}$ \\
\hline & & & V & $418.18 \pm 17.31^{b}$ & $59.46 \pm 3.68^{\mathrm{a}}$ \\
\hline & & C & $\mathrm{Vl}$ & $2038.33 \pm 114.80^{c}$ & $90.51 \pm 18.41^{c}$ \\
\hline & & & VII & $2585.46 \pm 99.56^{d}$ & $104.40 \pm 8.00^{c}$ \\
\hline \multirow[t]{7}{*}{ AST (U/L) } & $163.92 \pm 40.72$ & A & 1 & $348.49 \pm 34.50$ & $121.99 \pm 10.10$ \\
\hline & & & $\|$ & $346.23 \pm 36.88$ & $129.85 \pm 13.96$ \\
\hline & & B & III & $587.63 \pm 16.13^{b}$ & $114.34 \pm 12.22$ \\
\hline & & & IV & $652.02 \pm 34.83^{b}$ & $124.29 \pm 9.84$ \\
\hline & & & V & $1000.94 \pm 77.29^{b}$ & $140.45 \pm 21.18$ \\
\hline & & C & $\mathrm{Vl}$ & $2163.72 \pm 33.70^{d}$ & $222.83 \pm 23.62^{c}$ \\
\hline & & & VII & $2794.61 \pm 177.41^{d}$ & $239.03 \pm 44.12^{c}$ \\
\hline \multirow[t]{7}{*}{$\mathrm{DB}(\mu \mathrm{mol} / \mathrm{L})$} & $3.38 \pm 0.92$ & A & 1 & $3.40 \pm 0.51$ & $2.74 \pm 0.50$ \\
\hline & & & $\|$ & $4.01 \pm 0.20$ & $2.82 \pm 0.15$ \\
\hline & & B & III & $4.88 \pm 0.52$ & $3.28 \pm 0.11^{\mathrm{a}}$ \\
\hline & & & IV & $4.91 \pm 0.08$ & $3.33 \pm 0.15^{\mathrm{a}}$ \\
\hline & & & V & $4.96 \pm 0.35$ & $3.62 \pm 0.06^{b}$ \\
\hline & & C & $\mathrm{Vl}$ & $4.92 \pm 0.25$ & $4.14 \pm 0.24^{c}$ \\
\hline & & & VII & $5.35 \pm 0.63$ & $4.99 \pm 0.03^{d}$ \\
\hline \multirow[t]{7}{*}{$\mathrm{TB}(\mu \mathrm{mol} / \mathrm{L})$} & $9.51 \pm 0.29$ & A & 1 & $8.43 \pm 1.20$ & $8.43 \pm 1.20$ \\
\hline & & & $\|$ & $6.98 \pm 0.03$ & $7.02 \pm 0.12$ \\
\hline & & B & ॥ा & $10.75 \pm 0.44^{b}$ & $7.73 \pm 0.24$ \\
\hline & & & IV & $9.13 \pm 1.00^{b}$ & $9.26 \pm 0.23^{b}$ \\
\hline & & & V & $8.51 \pm 0.29^{b}$ & $9.47 \pm 0.44$ \\
\hline & & C & $\mathrm{Vl}$ & $11.44 \pm 0.21^{d}$ & $10.79 \pm 0.92^{c}$ \\
\hline & & & VII & $12.50 \pm 0.19^{d}$ & $12.06 \pm 0.35^{c}$ \\
\hline \multirow[t]{7}{*}{$\mathrm{LDH}(\mathrm{U} / \mathrm{L})$} & $733.18 \pm 102.0$ & A & 1 & $1421.22 \pm 276.70$ & $590.93 \pm 14.68$ \\
\hline & & & $\|$ & $1452.79 \pm 324.34$ & $736.05 \pm 146.78$ \\
\hline & & B & III & $2341.30 \pm 105.82$ & $939.20 \pm 43.17$ \\
\hline & & & IV & $1471.21 \pm 81.76$ & $725.76 \pm 154.91$ \\
\hline & & & V & $1549.70 \pm 163.10$ & $953.03 \pm 78.40$ \\
\hline & & C & $\mathrm{Vl}$ & $1562.79 \pm 55.89$ & $1889.12 \pm 96.55^{d}$ \\
\hline & & & VII & $1938.16 \pm 58.62^{d}$ & $2392.23 \pm 206.01^{d}$ \\
\hline
\end{tabular}

a $P<0.05$

${ }^{\mathrm{b}} P<0.01$ versus group $\mathrm{A}(\mathrm{I}-\mathrm{II})$

c $P<0.05$

d $P<0.01$ versus group $B($ III-V)

decreased. The transport and excretion capacity of liver cells may have been damaged accordingly, and the specific mechanism needs further research.

In this study, we found that $20 \mathrm{~min}$ and $50 \mathrm{~min}$ of ischemia time were related to two sudden changes in parameter b3. Groups A, B, and C, which were established by these two sudden changes, showed significant differences in serum liver function and histopathology, and the morphological recovery of cells occurred later than serological indicators. We found that the mortality in group C (41.7\%) was much higher than that in the other groups $(0 \%)$. In addition to the damage to liver function, part of the reason may be attributed to bowel congestion and infarction. This is understandable because, in the process of using ischemia-reperfusion as a representative factor, we must make the surgical approach as close as possible to the rat liver transplantation model to increase the reliability of the 


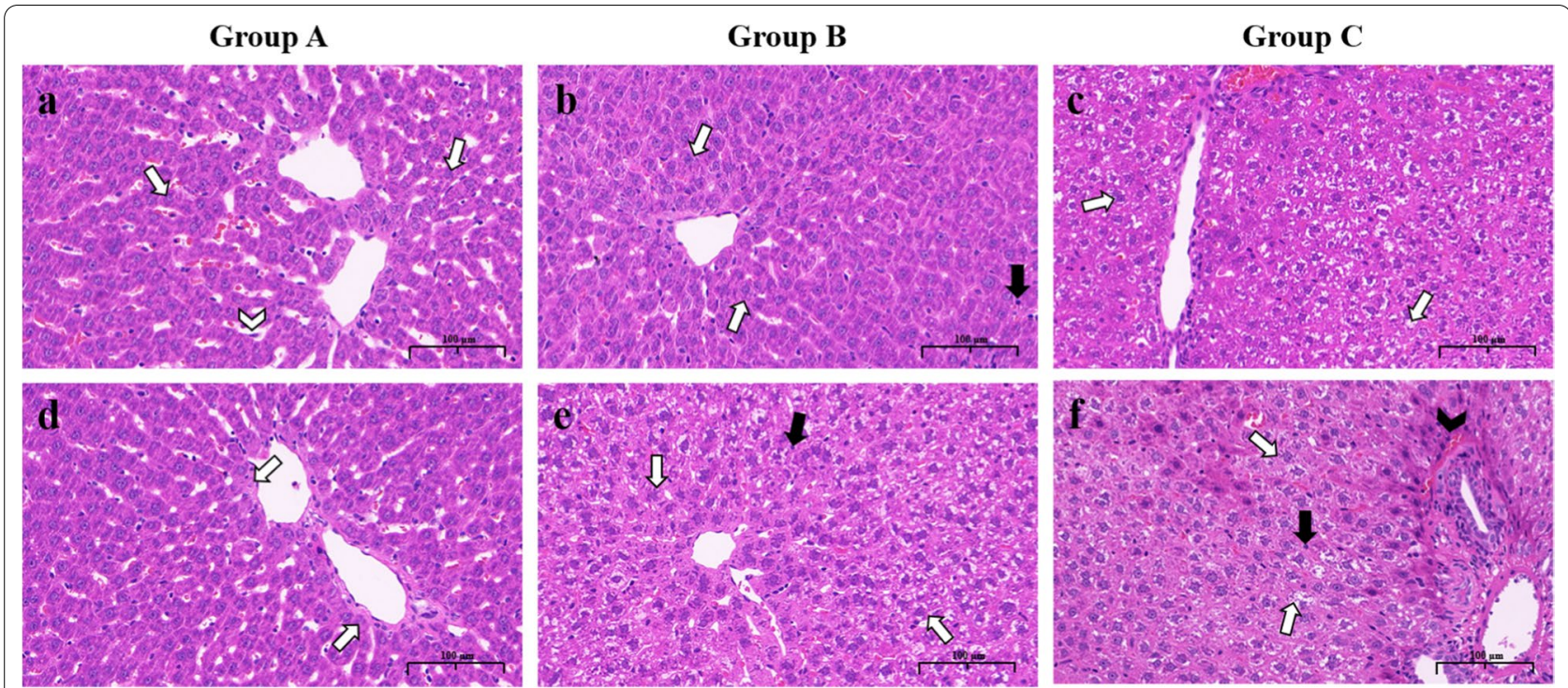

Fig. 4 Histological examination of the liver on POD 1 and POD 7 among groups $A, B$ and $C ; \mathbf{a}-\mathbf{c}$ Liver tissue on POD 1 in groups A-C; d-e Liver tissue on POD 7 in groups A-C

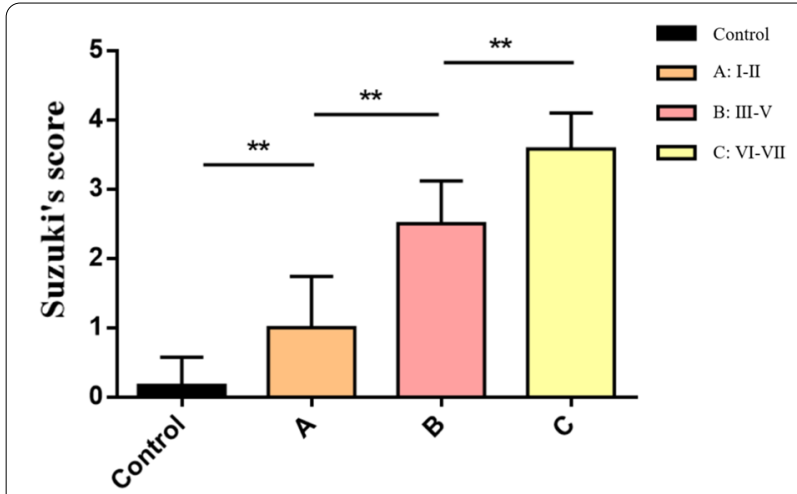

Fig. 5 Suzuki's scores among groups A, B and C were significantly different on POD 1. $(P<0.01)$

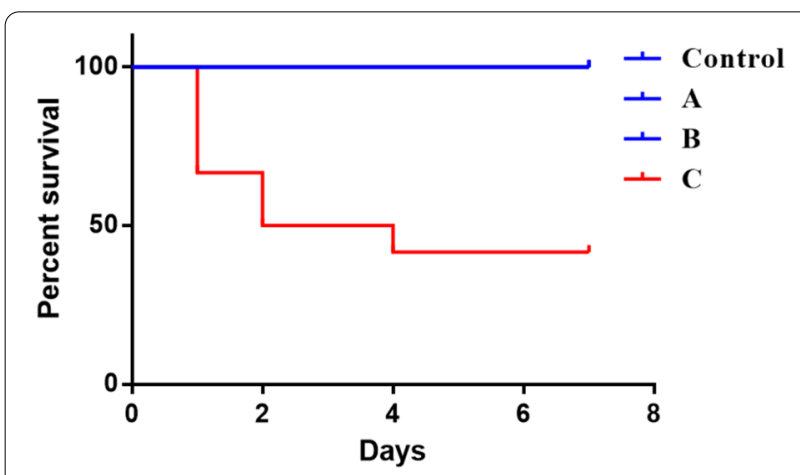

Fig. 6 The survival rate among the groups from POD 1 to POD 7. Seven rats in group $C$ died in 7 days, and 4 of them died on POD 1. No death happened in the other groups results. Other tests in our study also provide evidence that ICG fluorescence imaging has the potential to be used to quantitatively assess the quality of donor livers in different aspects.

Many previous studies [44-46] have concluded that liver transplantation in rats within 20 min of warm ischemia can achieve a better survival rate. After approximately $45 \mathrm{~min}$ of warm ischemia, the incidence of biliary obstruction and mortality increases after transplantation. These pieces of evidence prove that $\mathrm{b} 3$ may be used to classify liver quality.

The only difference between the control group and group I was whether the hepatic artery was ligated. Although the hepatic artery provides a smaller blood flow to the liver than the portal vein, it contains a large amount of oxygen, which provides for liver metabolism. In the FI curve, the b3 of the two groups was significantly different, but it was not seen in other inspection methods in this experiment. This suggests that ICG fluorescence imaging for detecting liver hypoxic-ischemic damage may be more sensitive than other testing methods.

Of course, this experiment takes ischemia-reperfusion injury as a representative factor as a preliminary study for the fluorescence assessment of the quality of the donor liver in liver transplantation, and we will carry out further experiments in the rat liver transplantation model. In this experiment, hepatic artery ligation was performed in the experimental groups to be consistent with the operation situation of the recipients in rat liver transplantation where hepatic artery ligation was required. 


\section{Conclusion}

The quantitative evaluation of liver function by ICG fluorescence imaging is feasible and effective in the ischemia-reperfusion model of rat liver, and it has the potential to be used in donor liver evaluation in a rat liver transplantation model in future studies.

\section{Abbreviations}

ICG: Indocyanine green; FI: Fluorescence intensity; POD: Postoperative day; ALT: Alanine aminotransferase; AST: Aspartate aminotransferase; TB: Total bilirubin; DB: Direct bilirubin; LDH: Lactic dehydrogenase; DCD: Donation after cardiac death; FDA: Food and drug administration; HIRI: Hepatic ischemia-reperfusion injury; SD: Sprague-Dawley; ROI: Region of interest.

\section{Acknowledgements}

The authors thank all the staff at the National Local Joint Engineering Research Center for Precision Surgery and Regenerative Medicine for their help and provision of facilities to carry out this study.

\section{Authors' contributions}

LS, HC, LY, RW, YL and TM designed and coordinated the study; LS, ZF and YW performed the experiment, RW, NZ and RW acquired and analyzed data; LS, ZF and HC interpreted the data; LS, HC wrote the manuscript; all authors approved the final version of the article. All authors read and approved the final manuscript.

\section{Funding}

Natural Science Basic Research Program of Shaanxi, No. 2020JQ-528. Institutional Foundation of The First Affiliated Hospital of Xi'an Jiaotong University, No. 2021QN-25

\section{Availability of data and materials}

The datasets generated and/or analyzed in the experiment are available from the corresponding author on reasonable request.

\section{Declarations}

\section{Ethics approval and consent to participate}

The rats were provided by the Experimental Animal Center of Xi'an Jiaotong University. The experimental procedure was approved by the Animal Ethics Committee of Xi'an Jiaotong University and complies with the Declaration of Helsinki. The study was carried out in compliance with the ARRIVE guidelines.

\section{Consent for publication}

Not applicable.

\section{Competing interests}

There isn't any relevant competing interests. There is no other relationships/ conditions that present a potential conflict of interest.

\section{Author details}

${ }^{1}$ National Local Joint Engineering Research Center for Precision Surgery and Regenerative Medicine, First Affiliated Hospital of Xi'an Jiaotong University, Xi'an 710061, China. ${ }^{2}$ Department of Hepatobiliary Surgery, The First Affiliated Hospital of Kunming Medical University, Kunming 650032, China. ${ }^{3}$ Department of Cardiovascular Surgery, First Affiliated Hospital of Xi'an Jiaotong University, Xi'an 710061, China.

Received: 20 July 2021 Accepted: 13 January 2022

Published online: 20 January 2022

\section{References}

1. The L. Organ donor research: towards a more effective system. Lancet (Lond, Engl). 2017;390(10106):1928.
2. Rodrigue JR, Feng S, Johansson AC, Glazier AK, Abt PL. Deceased donor intervention research: a survey of transplant surgeons, organ procurement professionals, and institutional review board members. Am J Transpl. 2016;16(1):278-86.

3. Van Pilsum Rasmussen SE, Henderson ML, Kahn J, Segev D. Considering tangible benefit for interdependent donors: extending a risk-benefit framework in donor selection. Am J Transpl. 2017;17(10):2567-71.

4. Slakter JS, Yannuzzi LA, Guyer DR, Sorenson JA, Orlock DA. Indocyaninegreen angiography. Curr Opin Ophthalmol. 1995:6(3):25-32.

5. Kaibori M, Kosaka H, Matsui K, Ishizaki M, Matsushima H, Tsuda T, Hishikawa H, Okumura T, Sekimoto M. Near-Infrared Fluorescence Imaging and Photodynamic Therapy for Liver Tumors. Frontiers in oncology. 2021;11:638327.

6. Charalampaki P, Nakamura M, Athanasopoulos D, Heimann A. Confocalassisted multispectral fluorescent microscopy for brain Tumor surgery. Front Oncol. 2019;9:583.

7. Lee JYK, Pierce JT, Thawani JP, Zeh R, Nie S, Martinez-Lage M, Singhal S. Near-infrared fluorescent image-guided surgery for intracranial meningioma. J Neurosurg. 2018;128(2):380-90.

8. Cho SS, Jeon J, Buch L, Nag S, Nasrallah M, Low PS, Grady MS, Singhal $S$, Lee JYK. Intraoperative near-infrared imaging with receptor-specific versus passive delivery of fluorescent agents in pituitary adenomas. J Neurosurg. 2018;131(6):1974-84.

9. Guan T, Shang W, Li H, Yang X, Fang C, Tian J, Wang K. From detection to resection: photoacoustic tomography and surgery guidance with indocyanine green loaded gold nanorod@liposome core-shell nanoparticles in liver cancer. Bioconjug Chem. 2017;28(4):1221-8.

10. Jimenez-Lillo J, Villegas-Tovar E, Momblan-Garcia D, Turrado-Rodriguez V, Ibarzabal-Olano A, De Lacy B, Diaz-Giron-Gidi A, Faes-Petersen R, Martinez-Portilla RJ, Lacy A. Performance of indocyanine-green imaging for sentinel lymph node mapping and lymph node metastasis in esophageal cancer: systematic review and meta-analysis. Ann Surg Oncol. 2021:28:4869-77.

11. Zhang X, Li Y, Zhou Y, Mao F, Lin Y, Guan J, Sun Q. Diagnostic performance of indocyanine green-guided sentinel lymph node biopsy in breast cancer: a meta-analysis. PLOS ONE. 2016;11(6):e0155597.

12. Sugie T, Kinoshita T, Masuda N, Sawada T, Yamauchi A, Kuroi K, Taguchi $\mathrm{T}$, Bando $\mathrm{H}$, Yamashiro $\mathrm{H}$, Lee $\mathrm{T}$, et al. Evaluation of the clinical utility of the ICG fluorescence method compared with the radioisotope method for sentinel lymph node biopsy in breast cancer. Ann Surg Oncol. 2016;23(1):44-50

13. Buda A, Crivellaro C, Elisei F, Di Martino G, Guerra L, De Ponti E, Cuzzocrea M, Giuliani D, Sina F, Magni S, et al. Impact of indocyanine green for sentinel lymph node mapping in early stage endometrial and cervical cancer: comparison with conventional radiotracer $(99 \mathrm{~m}) \mathrm{Tc}$ and/or blue dye. Ann Surg Oncol. 2016;23(7):2183-91.

14. Toh U, Iwakuma N, Mishima M, Okabe M, Nakagawa S, Akagi Y. Navigation surgery for intraoperative sentinel lymph node detection using Indocyanine green (ICG) fluorescence real-time imaging in breast cancer. Breast Cancer Res Treat. 2015;153(2):337-44.

15. De Nardi P, Elmore U, Maggi G, Maggiore R, Boni L, Cassinotti E, Fumagalli U, Gardani M, De Pascale S, Parise P, et al. Intraoperative angiography with indocyanine green to assess anastomosis perfusion in patients undergoing laparoscopic colorectal resection: results of a multicenter randomized controlled trial. Surg Endosc. 2020;34(1):53-60.

16. Rausa E, Zappa MA, Kelly ME, Turati L, Russo A, Aiolfi A, Bonitta G, Sgroi LG. A standardized use of intraoperative anastomotic testing in colorectal surgery in the new millennium: is technology taking over? A systematic review and network meta-analysis. Tech Coloproctol. 2019;23(7):625-31.

17. Buxey K, Lam F, Muhlmann M, Wong S. Does indocyanine green improve the evaluation of perfusion during laparoscopic colorectal surgery with extracorporeal anastomosis? ANZ J Surg. 2019;89(11):E487-e491.

18. Spartalis E, Ntokos G, Georgiou K, Zografos G, Tsourouflis G, Dimitroulis D, Nikiteas NI. Intraoperative indocyanine green (ICG) angiography for the identification of the parathyroid glands: current evidence and future perspectives. In vivo (Athens, Greece). 2020;34(1):23-32.

19. Gerken ALH, Nowak K, Meyer A, Weiss C, Krüger B, Nawroth N, Karampinis I, Heller K, Apel H, Reissfelder C et al: Quantitative assessment of intraoperative laser fluorescence angiography with indocyanine green predicts early graft function after kidney transplantation. Ann Surg 2020, Publish Ahead of Print. 
20. Forcione M, Chiarelli AM, Davies DJ, Perpetuini D, Sawosz P, Merla A, Belli A. Cerebral perfusion and blood-brain barrier assessment in brain trauma using contrast-enhanced near-infrared spectroscopy with indocyanine green: A review. J Cereb Blood Flow Metab. 2020;40(8):1586-98.

21. Ellebrecht DB, Warns T, Bürk CG, Thomaschewski M, Keck T, Bausch D. Quantitative intraoperative measurement of tissue perfusion of transplanted kidneys by indocyanine green angiography. Zentralbl Chir. 2020;145(1):57-63.

22. Dousse D, Vibert E, Nicolas Q, Terasawa M, Cano L, Allard MA, Salloum C, Ciacio O, Pittau G, Sa Cunha A, et al. Indocyanine green fluorescence imaging to predict graft survival after orthotopic liver transplantation: a pilot study. Liver Transpl. 2020;26(10):1263-74.

23. Saidi RF, Kenari SK. Liver ischemia/reperfusion injury: an overview. J Investig Surg. 2014;27(6):366-79.

24. Serracino-Inglott F, Habib NA, Mathie RT. Hepatic ischemia-reperfusion injury. Am J Surg. 2001;181(2):160-6.

25. Montalvo-Jave EE, Escalante-Tattersfield T, Ortega-Salgado JA, Piña E, Geller DA. Factors in the pathophysiology of the liver ischemia-reperfusion injury. J Surg Res. 2008;147(1):153-9.

26. Bellanti F. Ischemia-reperfusion injury: evidences for translational research. Ann Transl Med. 2016:4(Suppl 1):S55.

27. Peralta C, Jiménez-Castro MB, Gracia-Sancho J. Hepatic ischemia and reperfusion injury: effects on the liver sinusoidal milieu. J Hepatol. 2013;59(5):1094-106.

28. Behrends M, Martinez-Palli G, Niemann CU, Cohen S, Ramachandran R, Hirose R. Acute hyperglycemia worsens hepatic ischemia/reperfusion injury in rats. J Gastrointest Surg. 2010;14(3):528-35.

29. Saeed WK, Jun DW, Jang K, Chae YJ, Lee JS, Kang HT. Does necroptosis have a crucial role in hepatic ischemia-reperfusion injury? PLOS ONE. 2017;12(9):e0184752.

30. Dip F, Lo Menzo E, White KP, Rosenthal RJ. Does near-infrared fluorescent cholangiography with indocyanine green reduce bile duct injuries and conversions to open surgery during laparoscopic or robotic cholecystectomy? A meta-analysis. Surgery. 2021;169(4):859-67.

31. Bleszynski MS, DeGirolamo KM, Meneghetti AT, Chiu CJ, Panton ON. Fluorescent cholangiography in laparoscopic cholecystectomy: an updated Canadian experience. Surgical innovation. 2020;27(1):38-43.

32. Dip F, LoMenzo E, Sarotto L, Phillips E, Todeschini H, Nahmod M, Alle L, Schneider S, Kaja L, Boni L, et al. Randomized trial of near-infrared incisionless fluorescent cholangiography. Ann Surg. 2019;270(6):992-9.

33. Gangemi A, Danilkowicz R, Bianco F, Masrur M, Giulianotti PC. Risk factors for open conversion in minimally invasive cholecystectomy. JSLS J Soc Laparoendosc Surg. 2017;21(4):e2017.00062.

34. Osayi SN, Wendling MR, Drosdeck JM, Chaudhry UI, Perry KA, Noria SF, Mikami DJ, Needleman BJ, Muscarella P 2nd, Abdel-Rasoul M, et al. Near-infrared fluorescent cholangiography facilitates identification of biliary anatomy during laparoscopic cholecystectomy. Surg Endosc. 2015;29(2):368-75.

35. Lee Z, Sterling ME, Keehn AY, Lee M, Metro MJ, Eun DD. The use of indocyanine green during robotic ureteroenteric reimplantation for the management of benign anastomotic strictures. World J Urol. 2019;37(6):1211-6.

36. Ahmadi N, Ashrafi AN, Hartman N, Shakir A, Cacciamani GE, Freitas D, Rajarubendra N, Fay C, Berger A, Desai MM, et al. Use of indocyanine green to minimise uretero-enteric strictures after robotic radical cystectomy. BJU Int. 2019;124(2):302-7.

37. Lee Z, Moore B, Giusto L, Eun DD. Use of indocyanine green during robotassisted ureteral reconstructions. Eur Urol. 2015;67(2):291-8.

38. Chen Q, Shang W, Zeng C, Wang K, Liang X, Chi C, Liang X, Yang J, Fang C, Tian J. Theranostic imaging of liver cancer using targeted optical/MRI dual-modal probes. Oncotarget. 2017;8(20):32741-51.

39. Lee JY, Thawani JP, Pierce J, Zeh R, Martinez-Lage M, Chanin M, Venegas O, Nims S, Learned K, Keating J, et al. Intraoperative near-infrared optical imaging can localize gadolinium-enhancing gliomas during surgery. Neurosurgery. 2016;79(6):856-71.

40. Kaibori M, Matsui K, Ishizaki M, lida H, Sakaguchi T, Tsuda T, Okumura T, Inoue K, Shimada S, Ohtsubo S, et al. Evaluation of fluorescence imaging with indocyanine green in hepatocellular carcinoma. Cancer Imaging. 2016;16:6

41. Hoffmann C, Compton F, Schäfer JH, Steiner U, Fuller TF, Schostak M, Zidek W, van der Giet M, Westhoff TH. Intraoperative assessment of kidney allograft perfusion by laser-assisted indocyanine green fluorescence videography. Transpl Proc. 2010;42(5):1526-30.

42. Kawaguchi Y, Akamatsu N, Ishizawa T, Kaneko J, Arita J, Sakamoto Y, Hasegawa K, Kokudo N. Evaluation of hepatic perfusion in the liver graft using fluorescence imaging with indocyanine green. Int J Surg Case Rep. 2015;14:149-51.

43. Narasaki H, Noji T Fau - Wada H, Wada H Fau - Ebihara Y, Ebihara Y Fau Tsuchikawa T, Tsuchikawa T Fau - Okamura K, Okamura K Fau - Tanaka E, Tanaka E Fau - Shichinohe T, Shichinohe T Fau - Hirano S, Hirano S: Intraoperative real-time assessment of liver function with near-infrared fluorescence imaging (1421-9921 Electronic)

44. Ma Y, Wang GD, Wu LW, Hu RD. Dynamical changing patterns of histological structure and ultrastructure of liver graft undergoing warm ischemia injury from non-heart-beating donor in rats. World J Gastroenterol. 2006;12(30):4902-5.

45. He XS, Ma Y, Ju WQ, Wu LW, Wu JL, Liang YJ, Hu RD, Chen GH, Huang JF. Dynamic microcirculatory changes in liver graft from non-heart-beating donor with warm ischemia injury in rat. Hepatob Pancreat Dis Int HBPD INT. 2004;3(2):179-82

46. He XS, Ma Y, Wu LW, Ju WQ, Chen GH, Hu RD, Huang JF. Influence of warm ischemia injury on hepatic functional status and survival of liver graft in rats. Hepatobi Pancreat Dis Int HBPD INT. 2003;2(4):504-8.

\section{Publisher's Note}

Springer Nature remains neutral with regard to jurisdictional claims in published maps and institutional affiliations.

Ready to submit your research? Choose BMC and benefit from

- fast, convenient online submission

- thorough peer review by experienced researchers in your field

- rapid publication on acceptance

- support for research data, including large and complex data types

- gold Open Access which fosters wider collaboration and increased citations

- maximum visibility for your research: over $100 \mathrm{M}$ website views per year

At BMC, research is always in progress.

Learn more biomedcentral.com/submissions 